\title{
IDETC2016-60250
}

\section{THE DEVELOPMENT AND EFFECTS OF TEACHING PERSPECTIVE FREE-HAND SKETCHING IN ENGINEERING DESIGN}

\author{
Ethan Hilton \\ Georgia Institute of Technology \\ Atlanta, GA, USA \\ Meltem Alemdar \\ Georgia Tech, CEISMC \\ Atlanta, GA, USA
}

\author{
Wayne Li \\ Georgia Institute of Technology \\ Atlanta, GA, USA \\ Raghuram Pucha \\ Georgia Institute of Technology \\ Atlanta, GA, USA
}

\author{
Sunni H. Newton \\ Georgia Tech, CEISMC \\ Atlanta, GA, USA \\ Julie Linsey \\ Georgia Institute of Technology \\ Atlanta, GA, USA
}

\section{ABSTRACT}

As Computer-Aided Design software has become more advanced, the use of hand-drawn engineering drawings has greatly diminished. This reduction has led to free-hand sketching becoming less emphasized in engineering education. While many engineering curriculums formerly included courses dedicated entirely to sketching and hand drafting, these topics are no longer addressed by most current curriculums. However, it has been observed that sketching has many benefits including improved communication in the design process, idea generation exercises, and visualizing design ideas in threedimensional space. While isometric sketching has long been the preferred method in engineering curriculums, there are benefits of teaching perspective sketching including the creation of more realistic sketches for communication and idea generation.

This paper presents the development of a perspectivebased sketching curriculum and the study of how this method compares to more traditional methods of teaching sketching to students in a freshman level engineering graphics course.

The results show that the perspective-based sketching method leads to equivalent gains in spatial visualization skills and final design self-efficacy as the traditional method of teaching hand sketching. While maintaining these skills, the new method also taught students additional skills. Through surveys and interviews, the students expressed that these skills would be useful to them in their future coursework and careers.

\section{INTRODUCTION}

Several benefits have been found for teaching engineering students how to sketch. These include improving visualization skills, serving as stepping stones in the development of effective prototypes, and assisting in the design process by providing a method of tracking and developing ideas [1-5]. The traditional method of teaching sketching does prepare students to use the more modern CAD methods of creating representations by focusing on the sketching of simple objects in two-dimensional and isometric views and less on techniques to draw an object in realistic three-dimensions such as shading and perspective. While the CAD-focused method has been found useful in some applications, it runs the risk of missing out on benefits such as being able to quickly sketch to communicate an idea. Improving spatial visualization skills is often a critical outcome for CAD and visualization courses. Sorby (2009) says that the best way to improve these spatial skills is to "sketch, sketch, sketch" [1], but the more traditional method taught in engineering course does not focus on freehand sketching. Therefore, in a freshman-level mechanical/aerospace engineering course at Georgia Tech, we have begun to develop a more form and technique-based method of teaching free-hand sketching that is more commonly found in an Industrial Design or Architecture course.

As spatial visualization has been found important in many fields, there have been several tools developed to test these skills including the Purdue Spatial Visualization Test (PSVT) developed by Bodner and Guay (1997) and revised by Yoon (2011) and the Mental Rotation Test (MRT) developed by Vandenburg \& Kuse (1978) and Peters (2006) [6-11]. Also, curriculum changes or additions could affect Self-Efficacy for Engineering Design. Therefore, Carberry (2010) developed a method to determine design self-efficacy through four aspects: confidence, motivation, perceived success, and anxiety in performing engineering design tasks [12]. 


\section{TEACHING METHODS}

Sorby and Baartmans (2000) studied the impacts of a course specifically designed to improve Spatial Visualization skills including instruction on sketching [13]. However, only one method of sketching was taught and there has been little literature on how changes in sketching curriculum impact these skills. This section discusses the formation, ideologies, and motivation of the two methods for teaching sketching studied in this paper. The differences between the two methods are briefly observed, and the goals behind the creation of the Perspective method are discussed.

\section{Traditional Engineering Approach}

Introduction to Engineering Graphics and Visualization is a freshman engineering course in many universities. There is evidence that freshman cornerstone design courses enhance student interest in engineering and increase retention in engineering programs [14]. In 1999, when the Georgia Institute of Technology converted from quarter to semester curricula, the Schools of Mechanical Engineering and Civil and Environmental Engineering joined together to create a common, required, 3 credit hour introductory engineering graphics course for their undergraduates [15]. The fifteen-week course Engineering Graphics and Visualization included four weeks of sketching and eleven weeks of three-dimensional, constraint-based, solid modeling. The course is currently required for undergraduates in the Aerospace and Mechanical Engineering curricula. Initially (1999-2002) ME/CEE 1770 was a textbook based course. In 2002 summer semester, ME/CEE 1770 was revised using the "backward design" approach [16] with formative and summative assessments in lecture and lab activities. In later years project-based and learning-centered instructional approaches [17] were introduced. Such approaches follow a natural cycle of Kolb's learning model [18] which includes: abstract conceptualization, active experimentation / application, concrete experience, and reflective observation [19]. As ME/CEE 1770 was cross-listed with civil engineering until recently, the first four weeks of sketching was focused on isometric and orthographic sketching with dimensioning to create working drawings for manufacturing. Most of this sketching was done on lined graph paper and/or involved the use of straight edges and other drafting tools.

After sketching instruction in the first four weeks, the rest of the semester focuses on 2D and 3D CAD with project-based learning. Examples of these team projects from past semesters can be found at www.youtube.com/user/1770GT/videos. To summarize, in the context of engineering design, the traditional teaching methods (control in this paper) focused less on form and more on functionality and working drawings.

The use of sketching in design is well documented [20], as it serves as a tool to carry the design thought process While the use of sketching is extensively studied in the literature, very limited literature exists on the influence of various sketching methods (isometric versus perspective, see Figure 1) and sketching ability on the quality of the final design product. Some preliminary results suggest that designers who are given sketching instruction tended to draw more overall, but no conclusive correlations were found between the sketching skills and design outcome $[3,20]$. There is some literature available on the positive relationship between the amount of threedimensional 3D perspective sketching and design outcome [21]. With regards to orthographic projections and dimensioning aspects, it is observed that the quantity of dimensioned drawings created early in the design cycle is significantly linked with design outcome [22].

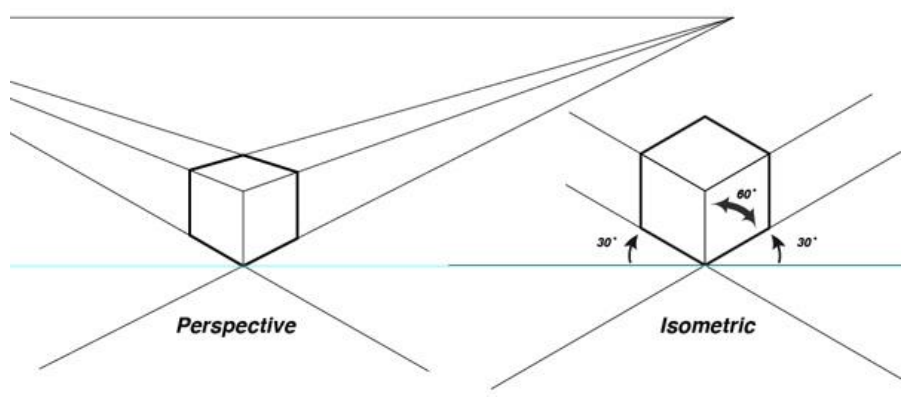

Figure 1: Perspective and Isometric Cubes

\section{Industrial Design Approach}

The Industrial Design-guided approach to teaching sketching only changed the first five to six weeks of the course when the curriculum was focused on teaching sketching. As opposed to the more traditional method outlined above, this method focuses much more on the form and technique of sketching itself and all sketching must be free-hand. Students are not allowed to use graph paper, rulers, or other aids. The students were taught about concepts of perspective and the techniques used to draw in one-, and two-point perspective.

Assignments using this method were more sketch-heavy and graded more heavily on the form of the sketches. These assignments included practice drawing simple shapes, but also included drawing objects in three-dimensions with uses of perspective and other techniques such as shading. These assignments began with simple shapes such as cubes and evolved to more complex shapes involving multiple different types of shapes in one sketch. This teaches students to recognize how to break complex objects down into simple primitives to begin their rendering and then enhance them to more detailed renderings.

The final project for the sketching portion of the class involved having students "invent" a product idea and present it using the sketching techniques learned in class. This allowed students to take an idea from conception and begin developing it using only their sketching abilities before using computeraided modeling software. After this portion of the class, the students follow a very similar curriculum to the sections taught in the traditional method of sketching. However, the students in this Experiment Group would use the renderings from their final sketching project as the basis for their CAD projects later in the class. This allows the student to go through the transition 
of creating an idea by hand on paper and implementing it into a computer-aided software, giving them practical experience in the functionality of learning to sketch in an engineering design environment.

\section{METHODOLOGY}

Data was collected on the impacts of these two methods in the Fall 2015 semester. Nine sections of the course, ME/CE 1770 were taught simultaneously by four different professors. One of the professors taught four of these sections using the traditional engineering method of teaching sketching in engineering. These four sections formed the control group for our study. The other five sections were taught by the remaining three professors using the Perspective method of teaching sketching. The students in these five sections formed the experiment group of the study.

In the first week of class, the students were asked to participate in the study by completing a brief sketching quiz and an online survey that included the two spatial visualization tests: the Purdue Spatial Visualization Test (PSVT) and the Mental Rotation Test (MRT) [6-10]. The students were also informed that they would be repeating this process at the end of the semester. Each data collection session took around 1.5 hours of the students' time and was performed during the lab portion of the lab-lecture class. The students were compensated through their choice of extra credit or monetary compensation.

The written portion of the data collection, the sketching quiz, had the students perform a variety of sketching exercises such as drawing straight lines, circles, squares, cubes, and a camera in 2-point perspective. After completing this portion of the study, the students were provided with a link to an online survey they completed during lab session. This online survey included basic demographics and both of the spatial visualization tests. The students were given 30 problems from the PSVT. They were not timed, but were told this quiz should take around 30-35 minutes. Only one correct answer was possible for each problem. Following the PSVT, the students were given 24 problems from the MRT. They were given these problems 12 at a time and were given 3 minutes to complete each section, for a total of 6 minutes to complete all 24 questions. Each problem had two correct answers and the student must mark them both in order to be awarded the point for that problem.

Two weeks before the end of the semester, the students took the "post-class" quizzes, again. The same quizzes and survey were given with the addition of Carberry's Design SelfEfficacy questionnaire [12]. This questionnaire consists of questions about the participants' Confidence, Motivation, Expected Success, and Anxiety when conducting Engineering Design. This is asked in a single question about Engineering Design (ED) and eight questions about the Engineering Design Process (EDP). The EDP responses were averaged to create a single score. Upon completion of the post-class data collection, each student chose their desired form of compensation.

In addition to this data, students in the Experiment Group were also asked to participate in group interview sessions. These group interviews were not a requirement to participate in the study or to receive compensation. These groups took place around 6 weeks into the semester, immediately after the sketching-focused portion of the course was completed and

Table 1: Demographic breakdown of students in study

\begin{tabular}{|c|c|c|c|}
\hline \multirow[b]{2}{*}{ Survey Questions } & \multicolumn{3}{|c|}{ Number of Participants } \\
\hline & Traditional & Perspective & Total \\
\hline \multicolumn{4}{|l|}{ What is your gender? } \\
\hline Male & 130 & 158 & 288 \\
\hline Female & 35 & 43 & 78 \\
\hline Prefer not to disclose & 1 & 1 & 2 \\
\hline \multicolumn{4}{|l|}{ What is your race/ethnicity? } \\
\hline White/Caucasian & 110 & 137 & 247 \\
\hline Black or African American & 8 & 7 & 15 \\
\hline American Indian or Alaskan Native & 2 & 1 & 3 \\
\hline Native Hawaiian or Other Pacific Islander & 1 & 1 & 2 \\
\hline Middle Eastern & 3 & 0 & 3 \\
\hline Asian & 50 & 57 & 107 \\
\hline Prefer not to disclose & 2 & 3 & 5 \\
\hline \multicolumn{4}{|c|}{ Do you consider yourself to be of Hispanic, Latino or Spanish origin? } \\
\hline No & 15 & 22 & 37 \\
\hline Yes & 148 & 178 & 326 \\
\hline Prefer not to disclose & 3 & 2 & 5 \\
\hline
\end{tabular}


consisted of between 4 and 8 students with one interviewer and one note-taker/facilitator. A total of 18 students participated. They lasted around one hour and were conducted outside of class time. Both audio and video recordings were made. The video recordings were destroyed after the decision that the interviews would not be transcribed.

The interviews were semi-structured with a set list of questions, and also the ability to let the conversation develop naturally. The questions aimed to gain a better understanding of the student's perception of the importance of sketching in engineering design, determine the effect the students felt the class had on their own sketching and design abilities, and allow for feedback on different aspects of the course.

Table 2: Statistical Properties

\begin{tabular}{|c|c|c|c|c|c|c|c|}
\hline \multirow{2}{*}{\multicolumn{4}{|c|}{ Group }} & \multirow{3}{*}{ Pearson } & \multicolumn{2}{|c|}{ Normality } & \multirow{3}{*}{$\frac{\text { Var }}{24.9}$} \\
\hline & & & & & W & p-value & \\
\hline \multirow{10}{*}{$\begin{array}{l}\frac{0}{0} \\
\frac{0}{0} \\
\frac{0}{0} \\
\stackrel{0}{0}\end{array}$} & \multirow{3}{*}{\multicolumn{2}{|c|}{$\sum_{\tilde{\Omega}}$}} & Pre & & 0.93 & $1.4 \mathrm{E}-07$ & \\
\hline & & & Post & - & 0.94 & $1.6 \mathrm{E}-06$ & 35.6 \\
\hline & & & Diff & - & 0.93 & $8.9 \mathrm{E}-07$ & 19.6 \\
\hline & \multirow{3}{*}{\multicolumn{2}{|c|}{ 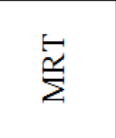 }} & Pre & - & 0.99 & 7.5E-03 & 22.4 \\
\hline & & & Post & - & 0.94 & $1.1 \mathrm{E}-06$ & 27.4 \\
\hline & & & Diff & - & 0.96 & $6.0 \mathrm{E}-05$ & 16.8 \\
\hline & \multirow{4}{*}{ 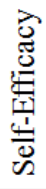 } & $\mathrm{C}$ & Post & 0.85 & 0.86 & $1.6 \mathrm{E}-11$ & 3.20 \\
\hline & & $\mathrm{M}$ & Post & 0.76 & 0.84 & 3.3E-12 & 3.99 \\
\hline & & $\mathrm{S}$ & Post & 0.88 & 0.86 & $2.8 \mathrm{E}-11$ & 4.03 \\
\hline & & A & Post & 0.88 & 0.92 & 8.3E-08 & 8.99 \\
\hline \multirow{10}{*}{ 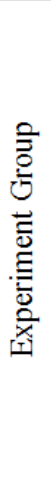 } & \multirow{3}{*}{\multicolumn{2}{|c|}{$\sum_{\infty}^{\infty}$}} & Pre & - & 0.95 & $1.2 \mathrm{E}-06$ & 22.6 \\
\hline & & & Post & - & 0.92 & $1.0 \mathrm{E}-08$ & 28.7 \\
\hline & & & Diff & - & 0.98 & $3.5 \mathrm{E}-02$ & 14.4 \\
\hline & \multirow{3}{*}{\multicolumn{2}{|c|}{$\stackrel{\hbar}{\stackrel{c}{z}}$}} & Pre & - & 0.98 & $3.5 \mathrm{E}-03$ & 22.5 \\
\hline & & & Post & - & 0.94 & $1.4 \mathrm{E}-07$ & 27.4 \\
\hline & & & Diff & - & 0.98 & $3.5 \mathrm{E}-03$ & 16.8 \\
\hline & \multirow{4}{*}{ 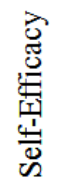 } & $\mathrm{C}$ & Post & 0.83 & 0.91 & 1.2E-09 & 2.85 \\
\hline & & $\mathrm{M}$ & Post & 0.84 & 0.87 & $2.5 \mathrm{E}-12$ & 3.59 \\
\hline & & $\mathrm{S}$ & Post & 0.89 & 0.89 & $6.1 \mathrm{E}-11$ & 3.76 \\
\hline & & A & Post & 0.88 & 0.94 & $1.9 \mathrm{E}-07$ & 8.67 \\
\hline
\end{tabular}

\section{RESULTS}

This section will discuss the results of the quizzes taken by the students before and after the course as well as comments from the group interviews. Table 1 shows the demographic break down of each group of students based on the student answers to the survey. The only data omitted from the analysis were from students who did not complete both portions of the study (pre-class and post-class quizzes). Students who began a quiz but left $50 \%$ or more of the answers blank were also discarded from the analysis.
The following figures show the class average score or average difference between the pre- and post-class quizzes to measure the spatial reasoning of the students. Significant differences, or lack-there-of, was determined using either a ttest or Repeated-Measure Analysis of Variance (RM-ANOVA) and the assumptions for each test were also verified [23, 24].

To determine normality, the Shapiro-Wilk with a chosen alpha level of 0.05 was performed on each group of interest [25]. The variance of each of these groups was also determined. These results are shown in Table 2. The Shapiro Wilk's test suggests a non-normal distribution, but this test can be affected by a large sample so Q-Q plots were also observed to check for normality. Figure 2 shows the Q-Q Plot for the MRT scores for all students. There is a slight positive skew, but it can be regarded as normal. The PSVT scores are similar. Based on this, the normality assumption is met.

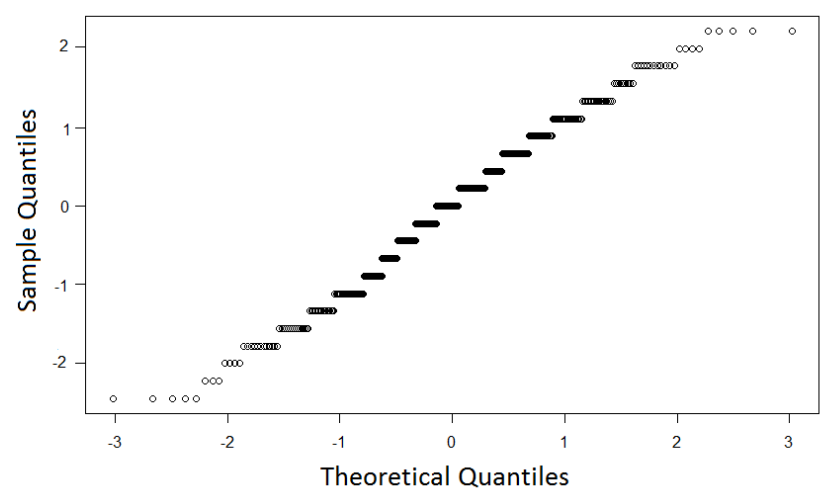

Figure 2: Normal Q-Q Plot- MRT Scores

Figure 3 shows the Q-Q Plot for the Design Self-Efficacy Motivation scores. The plot shows that this data is not normal. Therefore, the Mann-Whitney $U$ test was used to test for significant differences between the groups' self-efficacy scores [26]. All statistical analyses were performed using R Studio.

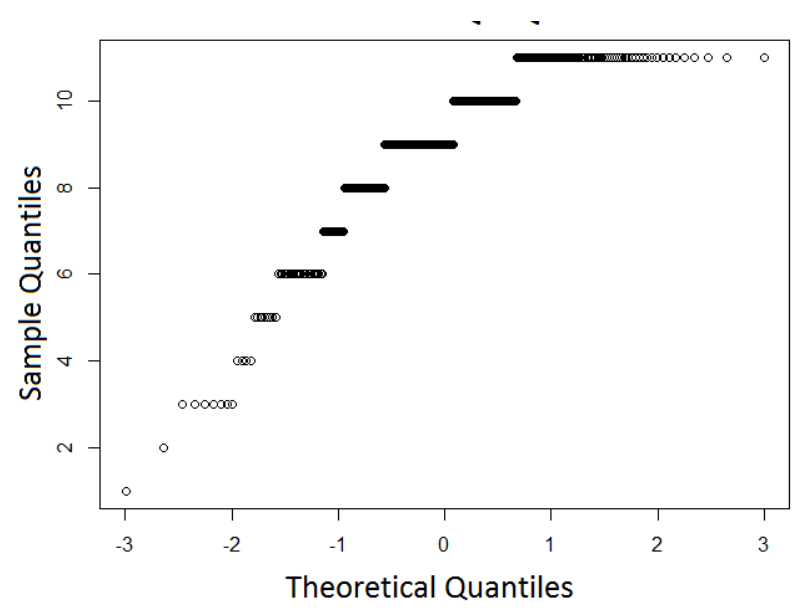

Figure 3: Skewed Q-Q Plot - Motivation Self-Efficacy 


\section{PSVT}

Figure 4 shows the comparison of pre- and post-class scores. Both data sets are normal, and have similar variances. We ran RM-ANOVA comparing pre and post scores and found p-values of 0.67 for participants in the Traditional class and 0.83 for participants in the Perspective class, indicating the pre to post scores are not significantly different.

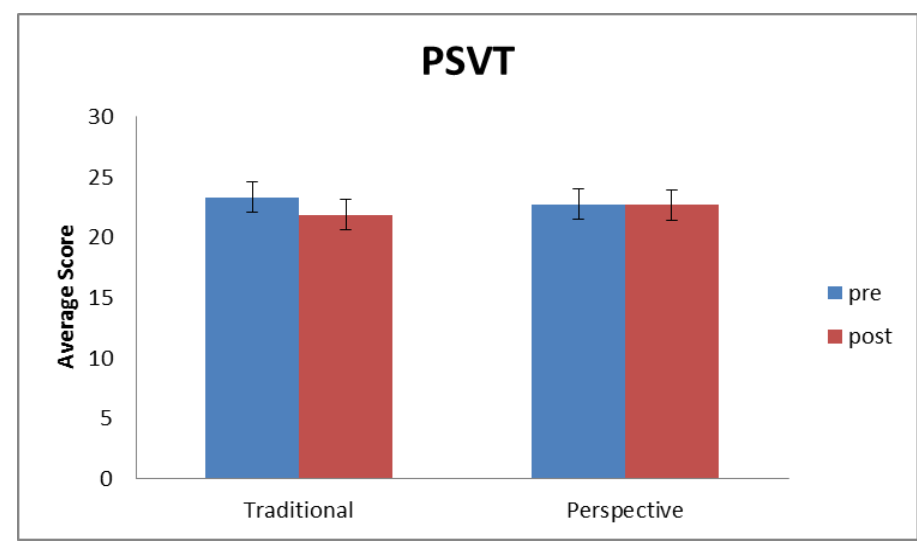

Figure 4: Average PSVT Scores

MRT

Figure 5 shows the comparison of pre- and post-class scores for both groups for the MRT quiz. Both data sets are normal, and have similar variances. We ran RM-ANOVA and found a p-value of less than 0.01 in both cases, indicating the two sets of pre/post tests are significantly different, with the post-quiz scores being higher than the pre-quiz scores.

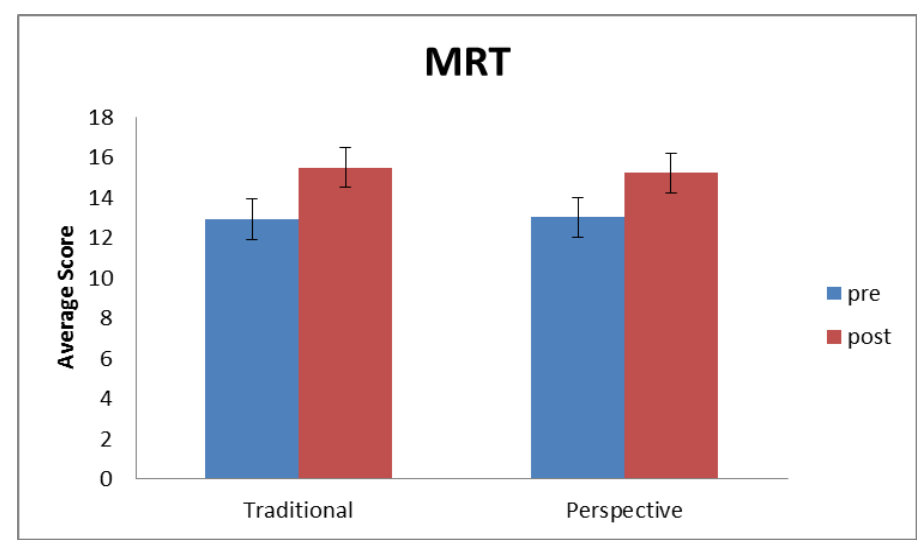

Figure 5: Average MRT Scores

Figure 6 shows the difference between the pre- and postclass scores for the MRT quiz for each group and compares the two groups' changes. Both data sets are normal, and have similar variances. As these are independent groups, a t-test is run and finds a p-value of 0.89 , indicating the groups are NOT significantly different. As seen in Figure 5Figure 4, both groups' scores rose significantly, but the rise in each groups' scores are statistically equivalent.

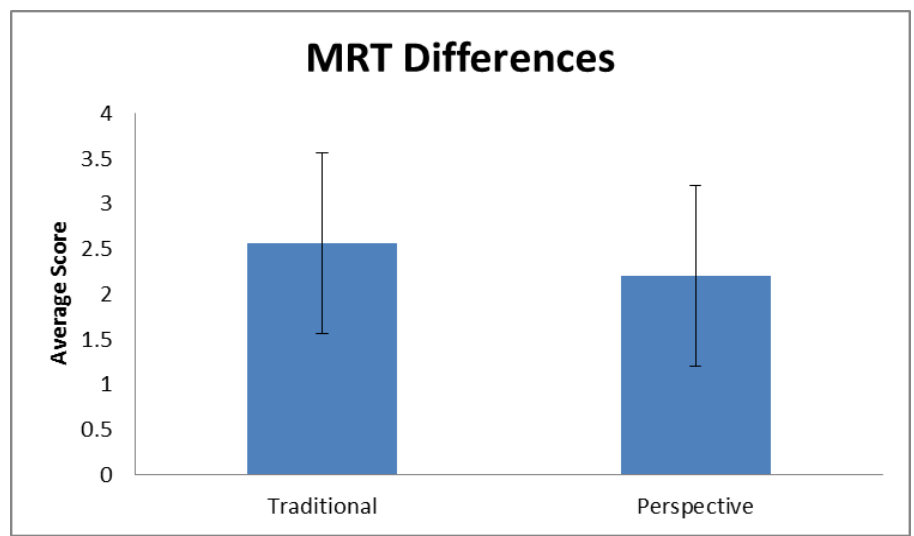

Figure 6: Change in MRT Scores

\section{Self-Efficacy}

Table 2 shows that for each of the Self-Efficacy scores for both groups, the Pearson Correlation between the Engineering Design (ED) and Engineering Design Process (EDP) scores scored higher than the acceptable rate of 0.70 as suggested by Carberry (2010) [12]. Therefore, the two scores can be deemed as equivalent. For the following figures, we will use the ED scores to compare the Traditional Class students to the Perspective Class students.

Figure 7 shows the comparison of Self-Efficacy Scores between the Traditional and Perspective Classes for each SelfEfficacy Metric. We ran a Mann-Whitney U test between the two groups and found the following results:

- Confidence:

$$
\mathrm{U}=15664, \mathrm{p} \text {-value }=0.39
$$

- Motivation:

$$
\mathrm{U}=15213 \text {, p-value }=0.71
$$

- Success:

$$
\mathrm{U}=14586, \mathrm{p} \text {-value }=0.75
$$

- Anxiety:

$$
\mathrm{U}=14100, \mathrm{p} \text {-value }=0.40
$$

These scores suggest that all aspects of Design SelfEfficacy are statistically equivalent between the two groups.

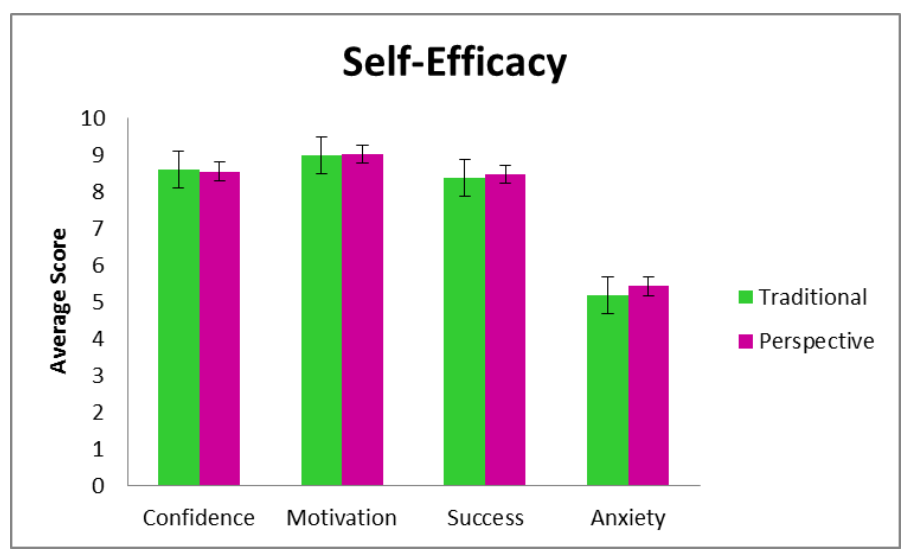

Figure 7: Design Self-Efficacy Scores 


\section{Focus Groups}

In the group interviews held after the sketching portion of the class was over, the students in the Perspective Class had overall approving statements in regards to the sketching curriculum. When asked the question, "How good of a sketcher do you perceived yourself to be?" all four groups had a majority positive response. One student responded (with general agreement from his classmates) "I feel much more confident in my ability to quickly sketch something if I were to need to." Students also spoke of enjoying the homework as being "a nice break from their typical engineering homework" as it "allowed them to be more creative."

Ultimately, the group interviews allowed us to see where the students felt the class was excelling and where it needed improvement. The overall positive view of the class was encouraging for us and helpful as we continue to develop the curriculum.

\section{CONCLUSIONS}

The data presented in the results section bring us to several important conclusions. Firstly, the data shows that the newer curriculum was as effective as the traditional curriculum for visualization skills. Both groups saw significant increases in their scores on the Mental Rotation Test (MRT) over the semester. When comparing these increases, there was no significant difference between the increases experienced by the two groups. For the Purdue Spatial Visualization Test (PSVT), neither group saw a statistically significant change in the scores.

Finally, the data collected as part of the Design Self-Efficacy Survey showed no significant differences between the Traditional and Perspective Classes in confidence, motivation, success, or anxiety. All of this data suggests that this method of teaching perspective sketching skills to engineering students leaves the students in just as good, if not slightly better, at the end of class in terms of important skills such as spatial visualization and with nearly identical Self-Efficacy in Engineering Design when compared to the students being taught only isometric sketching techniques. Students in the Experiment group are very likely increasing their free-hand sketching in perspective skills significant. These data, along with the highly positive feedback from group interviews, suggest that the curriculum is quickly heading in the right direction. The data suggest that the Perspective approach to teaching sketching likely garners the same benefits for visualization while also teaching the critical skill of perspective free-hand sketching.

\section{FUTURE WORK}

This section will discuss needs we are currently striving to meet as well as briefly discuss other work that is being done in an effort to better understand how to create the most effective method for teaching students how to sketch and how to more effectively assess what the student sketching ability.

\section{Continued data collection}

As mentioned in the Methodology section, there was one professor who taught the "traditional" method of sketching in fall 2015 to four sections of the course while three other professors taught the remaining five class sections using the newer Perspective method. This, while unavoidable for this semester, leads to many obvious problems. We bear the possibility that any differences seen between the two groups are an effect of not only different teaching methods, but in the different instructor. For example, the professor teaching the traditional method has more experience teaching the course than all of the other instructors.

Fortunately, after hearing student feedback and seeing the quality of work produced by students in other sections, the more experienced professor has begun to incorporate more of the new teaching method into the class. By continuing to gather data for the sections taught by this professor, it will allow for the instructor confound to be eliminated.

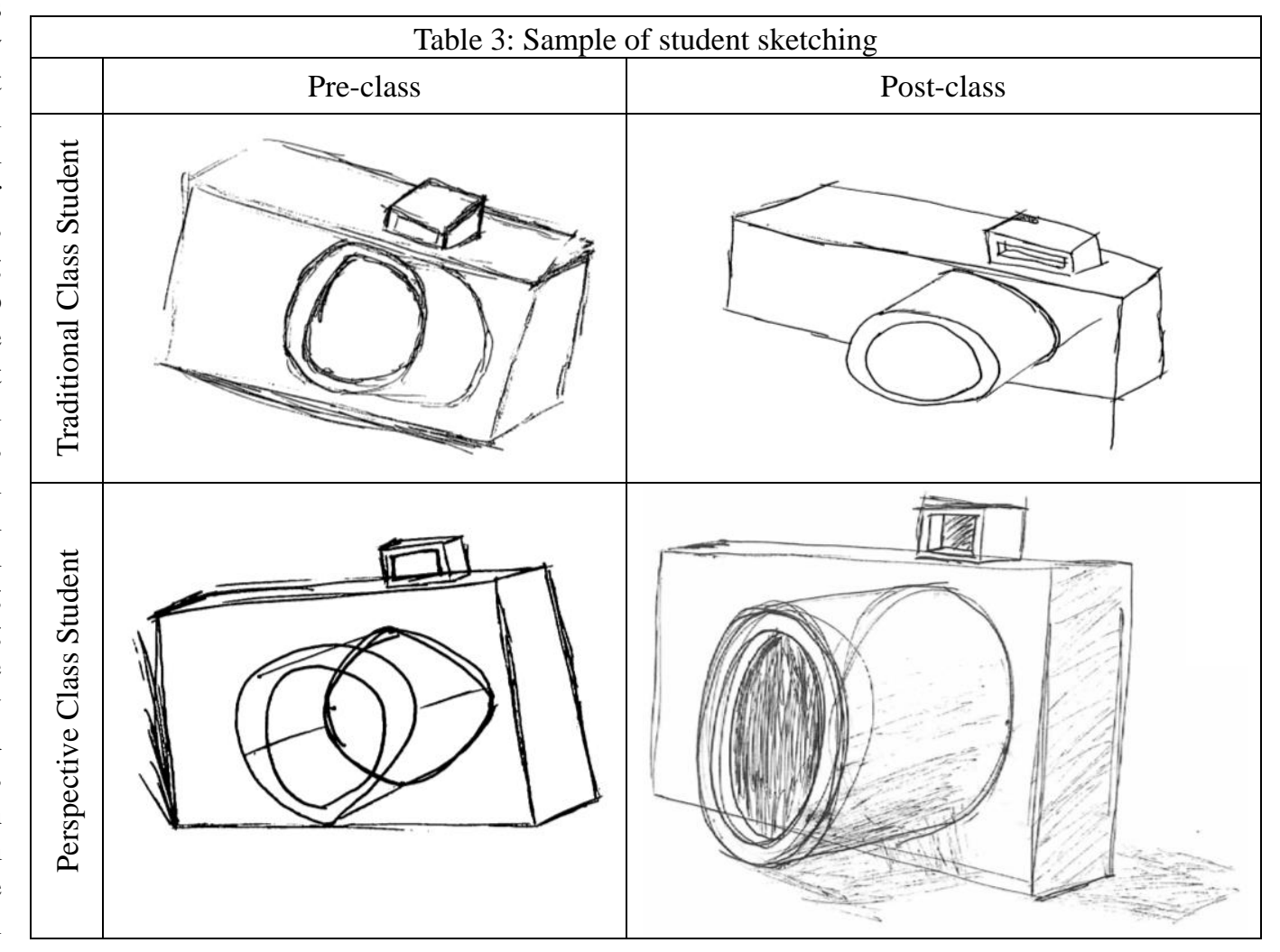




\section{More complete data collection}

Also mentioned in the Methodology section were sketching quizzes given to the students as part of data collection. These quizzes allowed for a sample of a student's data to be collected. Table 3 shows a small sample of the sketches collected. These drawing came from two typical students, one in each of the groups. It is easy to see that both students made improvements to their sketching ability over the course of the semester. However, there is currently no way to reliably and quantitatively compare how much better each student got during the course. Therefore, the authors are currently working on an effective way to quickly, accurately, and consistently evaluate sketches [27]. Developing this rubric would allow for a wide array of studies to be carried out, beginning with evaluating how different methods of teaching sketching impacts a student's actual sketching ability.

\section{Development of Online Sketching Tutor}

One of the most challenging things about teaching student sketching techniques such as perspective and shading is these are not topics most engineering faculty are familiar with and class size tends to be rather large. As this type of sketching has not been the norm for engineering curricula, very few engineering professors have the skills or experience required to teach these methods. Therefore, it is necessary to either train engineering professors in these skills so they can teach them to their students or bring in experienced instructors from other departments such as Industrial Design or Architecture. This is not always cost effective or even possible for institutions with smaller art departments. Even if there is a skilled professional available to teach the course, it is difficult for them to give active feedback to students due to ever-increasing class sizes.

The authors are currently working with Computer Science researchers to develop an online sketching tutor that gives immediate feedback called Persketchtivity [28]. We believe the development of this program is not only useful but will become necessary in order to more fully develop and prepare the next generation of students to more effectively conduct engineering design.

\section{ACKNOWLEDGMENTS}

The authors would like to thank Dr. Tracy Hammond and the Sketch Recognition Lab at Texas A\&M University for their work on Persketchtivity, an online sketch-based tutor, and the continual contributions made to the research in the area of effectively teaching students to sketch, as well as the creation of the online survey used for data collection in this project. The authors would like to thank Blake Williford for his help in the creation of the sketching quiz used to collect student sketching samples, and Dr. Katherine Fu and Dr. Dennis Dorozhkin for allowing the use of their class time to collect data.

Finally, the authors would like to thank the National Science Foundation, through which this research is partially funded the NSF Cyberlearning grant no. 1441331 and NSF grant no. 1238089. Any opinions, findings, and conclusions or recommendations expressed in this material are those of the authors and do not necessarily reflect the views of National Science Foundation.

\section{REFERENCES}

[1] S. A. Sorby, "Educational research in developing 3-D spatial skills for engineering students," International Journal of Science Education, vol. 31, pp. 459-480, 2009.

[2] E. Hilton, J. Linsey, and J. Goodman, "Understanding the Prototyping Strategies of Experienced Designers," presented at the Frontiers in Education Conference (FIE), El Paso, TX, USA, 2015.

[3] J. G. Cham and M. C. Yang, "Does Sketching Skill Relate to Good Design?," in ASME 2005 International Design Engineering Technical Conferences and Computers and Information in Engineering Conference, 2005, pp. 301-308.

[4] M. C. Yang, "Observations on concept generation and sketching in engineering design," Research in Engineering Design, vol. 20, pp. 1-11, 2009.

[5] S. Olkun, "Making connections: Improving spatial abilities with engineering drawing activities," International Journal of Mathematics Teaching and Learning, vol. 3, pp. 1-10, 2003.

[6] S. Y. Yoon, Psychometric Properties of the Revised Purdue Spatial Visualization Tests: Visualization of Rotations (The Revised PSVT-R): ERIC, 2011.

[7] S. Shepard and D. Metzler, "Mental rotation: effects of dimensionality of objects and type of task," Journal of Experimental Psychology: Human Perception and Performance, vol. 14, p. 3, 1988.

[8] S. G. Vandenberg and A. R. Kuse, "Mental rotations, a group test of three-dimensional spatial visualization," Perceptual and motor skills, vol. 47, pp. 599-604, 1978.

[9] M. Peters, W. Lehmann, S. Takahira, Y. Takeuchi, and K. Jordan, "Mental rotation test performance in four cross-cultural samples $(n=3367)$ : Overall sex differences and the role of academic program in performance," Cortex, vol. 42, pp. 10051014, 2006.

[10] Y. Maeda and S. Y. Yoon, "A meta-analysis on gender differences in mental rotation ability measured by the Purdue spatial visualization tests: Visualization of rotations (PSVT: R)," Educational Psychology Review, vol. 25, pp. 69-94, 2013.

[11] G. M. Bodner and R. B. Guay, "The Purdue visualization of rotations test," The Chemical Educator, vol. 2, pp. 1-17, 1997.

[12]A. R. Carberry, H. S. Lee, and M. W. Ohland, "Measuring engineering design self-efficacy," Journal of Engineering Education, vol. 99, pp. 71-79, 2010.

[13] S. A. Sorby and B. J. Baartmans, "The Development and Assessment of a Course for Enhancing the 3-D Spatial Visualization Skills of First Year Engineering Students," Journal of Engineering Education, vol. 89, pp. 301-307, 2000. [14] J. Richardson and J. Dantzler, "Effect of a freshman engineering program on retention and academic performance," 
in Frontiers in Education, 2002. FIE 2002. 32nd Annual, 2002, pp. S2C-16-S2C-22 vol. 3.

[15] D. Elrod and M. D. Stewart, "Assessing student work in engineering graphics and visualization course," Engineering Design Graphics Journal, vol. 69, 2009.

[16] G. Wiggins and J. McTighe, "Understanding by design. Alexandria, VA: ASCD," in Assessment for Learning Conference Ljubljana, June, 1998.

[17] R. V. Pucha and T. T. Utschig, "Learning-Centered Instruction of Engineering Graphics for Freshman Engineering Students," Journal of STEM Education: Innovations and Research, vol. 13, p. 24, 2012.

[18] A. W. Combs, "Fostering maximum development of the individual," Issues in secondary education, pp. 65-87, 1976.

[19] M. Suwa and B. Tversky, "What do architects and students perceive in their design sketches? A protocol analysis," Design studies, vol. 18, pp. 385-403, 1997.

[20] M. C. Yang and J. G. Cham, "An analysis of sketching skill and its role in early stage engineering design," Journal of Mechanical Design, vol. 129, pp. 476-482, 2007.

[21] S. Song and A. M. Agogino, "Insights on designers' sketching activities in new product design teams," in $A S M E$ 2004 International Design Engineering Technical Conferences and Computers and Information in Engineering Conference, 2004, pp. 351-360.
[22] M. C. Yang, "An examination of prototyping and design outcome," in ASME 2004 International Design Engineering Technical Conferences and Computers and Information in Engineering Conference, 2004, pp. 497-502.

[23] F. E. Ritter, J. W. Kim, J. H. Morgan, and R. A. Carlson, Running Behavioral Studies With Human Participants: A Practical Guide: A Practical Guide: Sage Publications, 2012.

[24] B. G. Tabachnick and L. S. Fidell, Experimental designs using ANOVA: Thomson/Brooks/Cole, 2007.

[25] P. Royston, "Approximating the Shapiro-Wilk W-Test for non-normality," Statistics and Computing, vol. 2, pp. 117-119, 1992.

[26] D. Clark-Carter, Doing quantitative psychological research: From design to report: Psychology Press/Erlbaum (UK) Taylor \& Francis, 1997.

[27] E. Hilton, B. Williford, W. Li, E. McTigue, T. Hammond, and J. Linsey, "Consistently Evaluating Sketching Ability in Engineering Curriculum," presented at the International Conference on Design Creativity (ICDC), Atlanta, GA, 2016. [28] B. Williford, P. Taele, T. Nelligan, W. Li, J. Linsey, and T. Hammond, "Persketchtivity: an intelligent pen-based educational application for design sketching instruction," in Revolutionizing Education with Digital Ink, ed: Springer, 2016, pp. 115-127. 